\title{
An Exploratory Study of Beliefs about Foreign Language Learning Among Self-Learners of English in Saudi Arabia
}

\author{
Nouf Aljasir \\ Assistant Professor of Applied Linguistics, \\ English Language Institute, \\ King Abdulaziz University, \\ Jeddah, Saudi Arabia
}

DOI: https://doi.org/10.36941/jesr-2022-0005

\begin{abstract}
This mixed-method exploratory study was conducted to investigate the types of beliefs that Saudi selflearners of English as a foreign language bring to the learning process. It also examined the possible links between those beliefs and self-rated English proficiency and explored whether individual factors, such as age and gender, played a role in shaping the learners' beliefs. Data were collected from 243 participants, using three instruments, two quantitative and one qualitative. The first was the Background Information Questionnaire, which was designed specifically for this study and consisted of two parts. The first part collected demographic data about the learners, and the second part elicited the participants' self-rated English proficiency in the four basic skills of listening, speaking, reading, and writing. The second questionnaire was a modified version of Horwitz's (1985) Beliefs about Language Learning Inventory (BALLI) and consisted of 27 items. The qualitative data were collected using one-on-one retrospective interviews, mainly to support and interpret the questionnaire results. The findings revealed that the beliefs of the participants were mostly realistic. Further, a significant positive correlation at the on level was found between the learners' belief that they had foreign language aptitude and their self-rated English proficiency. The results of independent samples t-tests revealed two significant differences in learner beliefs according to gender and four significant ones according to age. The study concluded by offering recommendations and suggestions for further research in the field.
\end{abstract}

Keywords: learner belief, foreign language learning, self-learner, self-rated proficiency

\section{Introduction}

Learners worldwide hold a myriad of beliefs about foreign language learning. These include beliefs about the status of the foreign language, the language learning process, the potential outcomes, and the individual's learning capabilities (Sakui \& Gaies, 1999). Horwitz (1985, p. 333) views language learner beliefs as "preconceived ideas about how languages are learned and how they should be taught." These beliefs generally reflect the outcomes of previous learning experiences and influence subsequent ones. White (1999) also suggests that "the belief systems learners hold or develop help them to adapt to new environments, to define what is expected of them and to act in accordance with those understandings." According to cognitive psychology, these beliefs constitute an essential part of 
learners' metacognitive knowledge (see Wenden, 1998). Previous research on foreign language learning has found that learner beliefs are linked to language proficiency and are likely to influence learning outcomes (see, for example, Huang \& Tsai, 2003; Mantle-Bromley, 1995; Mori, 1999; Peacock, 1999; Polat, 2009). As Riley (2009, p. 103) succinctly explains, "If learner beliefs are consistent with accepted good learning practices, or at least the practices of the current learning setting, then the effect of the beliefs is likely to be beneficial, and the learning outcomes positive." On the other hand, "erroneous beliefs about language learning lead to less effective language learning strategies" (Horwitz, 1987, p. 126).

Interest in studying language learner beliefs started in the 1980 os with the two pioneering studies of Horwitz (1985) and Wenden (1986). Horwitz (1985) examined students' beliefs about language learning and teaching in a foreign language methods course in the United States. Data were collected using two instruments: the Foreign Language Attitude Survey (FLAS) and the Beliefs about Language Learning Inventory (BALLI). The findings suggested that the beliefs the participants held could hinder their language learning process. Horwitz (1985) therefore recommended a systematic assessment of language learners' beliefs in order to increase their satisfaction and success in learning. In her interview-based study, Wenden (1986) investigated different types of knowledge about language learning as perceived by 25 adults in the United States. The results led Wenden (1986, p. 199) to urge teachers to "discover what their students believe or know about their learning, and to provide activities that would allow students to examine these beliefs and their possible impact on how they approach learning."

A review of the research that has been conducted in the field over the past four decades reveals that the majority of studies have predominantly aimed to investigate the beliefs that learners hold about language learning in formal educational settings. These settings include both second language learning (e.g., Al-Osaimi \& Wedell, 2014; Chawhan \& Oliver, 2000; Erlenawati, 2002; Horwitz, 1987, 1988; Kern, 1995; Tanaka \& Ellis, 2003; Wenden, 1986) and foreign language learning contexts (e.g., Aziz \& Quraishi, 2017; Benson \& Lor, 1999; Mori, 1999; Peacock, 1999; Polat, 2009; Sakui \& Gaies, 1999; Wen \& Johnson, 1997; Yang, 1999). Various data collection instruments were employed in these studies, including closed- and open-ended questionnaires, classroom observations, stimulated recalls, and interviews. Whereas some of these studies have attributed the differences found among the learners to their different cultural backgrounds, some have associated them with differences in instructional approaches (see Horwitz, 1999). Nevertheless, the studies have generally suggested that language teachers should play an active part in assessing their learners' beliefs and modifying those not consistent with good learning practices.

A few studies have been concerned with examining the possible relationships between learner beliefs and language proficiency. Mori (1999), for example, designed a belief questionnaire to assess the beliefs of 187 American college students learning Japanese as a foreign language. The data analysis revealed a statistically significant relationship between the learners' beliefs and their achievement. The learners who believed that Japanese was an easy language to learn outperformed those who considered it difficult. According to Mori (1999, p. 398), "these correlations could be interpreted in two ways. One interpretation is that students who find Japanese easy are normally high-ability students. The correlations could also mean that learners are likely to decide that Japanese is easy when they do well in class." Similar findings were reported by Huang and Tsai (2003), who used interviews and surveys to examine the possible differences in learner beliefs among high school students with high and low English proficiency levels. The findings showed that high-proficiency learners held more positive language learning beliefs than their low-proficiency peers.

There have been a few studies investigating language learners' beliefs in Saudi Arabia and the Arab world in general. Using a modified version of BALLI, Diab (2006) examined the beliefs held by 284 university students regarding learning English and French in Lebanon. The results showed that the learners believed that English was easier and more important to learn than French. The researcher attributed these findings to the learners' language learning background and their motivation to learn English. Interestingly, the findings were also relevant to the "political and socio- 
cultural contexts of foreign language education in Lebanon" (Diab, 2006, p. 91). Alsamaani (2012) also employed a modified version of BALLI to investigate the beliefs of 250 university students in Saudi Arabia about learning English. The researcher found that the learners generally had positive and realistic beliefs about their English learning. He concluded the study by pointing out that "identification of learners' beliefs and reflection on their possible effect on language learning may lead to increased awareness and even adjustment of their expectations" (Alsamaani, 2012, p. 51). In another BALLI study, Al-Roomy (2015) collected data from 151 Saudi university students to examine their beliefs about English language learning. The findings revealed that the students were uncertain about their foreign language learning aptitude; however, their beliefs were positive towards their language learning motivation and expectations, as well as towards their learning and communication strategies. A similar, more recent quantitative study was conducted by Al-malki and Javid (2018) to collect data from 118 university students in Saudi Arabia. The analysis of the BALLI data showed that the learners held positive beliefs about their English learning aptitude. They also believed that learning a language in childhood was easier than in adulthood and that extensive practice was important for ultimate success. As we can see, a few conflicting findings were obtained between Alsamaani's (2012) and Al-Roomy's (2015) studies, on the one hand, and Al-malki and Javid's (2018) study on the other. Since the learners in both studies had similar language and cultural backgrounds, the differences could be attributed to different instructional approaches (see Horwitz, 1999). Unfortunately, both studies depended on quantitative data collection only. The integration of qualitative data sources, such as interviews, would have been useful to explain the findings.

This mixed-method research represents an initial step to address this issue, but with a different target population. First, to the best of my knowledge, no attempt has yet been made to address the beliefs held by self-learners of foreign languages, a group that, in this study, has the same cultural background as school and university students but differs in age, learning purpose, and learning context. Self-learning is generally viewed as "a process by which individuals take the initiative, with or without the assistance of others, in diagnosing their learning needs, formulating learning goals, identifying human and material resources for learning, and evaluating learning outcomes" (Knowles, 1975, p. 18). The proliferation and advances in language learning resources in recent years have undoubtedly contributed to the rapid growth of this group. The present study contributes to the previous research in the language-learning field, with the aim of developing an understanding of the types of beliefs that self-learners bring to the foreign language learning process. It also aims to explore the possible links between those beliefs and self-rated English proficiency and whether individual factors, such as age and gender, play a role in shaping learner beliefs. Identifying and assessing those beliefs could ultimately help learners develop "a critical and informed awareness of learning options" (Wenden, 1986, p. 199). This inquiry is guided by the following four questions:

1. What beliefs do Saudi self-learners of English hold about foreign language learning?

2. Is there a relationship between the learners' beliefs and their self-rated English proficiency?

3. Is there a difference in learners' beliefs according to their gender?

4. Is there a difference in learners' beliefs according to their age?

\section{Method}

This exploratory study employed a mixed-method design, in which quantitative and qualitative data were collected and triangulated in the analysis.

\subsection{Participants}

To achieve the objectives of this study, purposive sampling was used to select the participants. The targeted individuals were non-English majors/graduates who were self-studying English for at least five hours a week and who had never studied a foreign language abroad. A total of 243 participants, all Saudi, with Arabic as their first language, constituted the main study sample. Both male and 
female learners were included, and their ages ranged from 21 to 40, as shown in Table 1.

Table 1: Participants' Demographic Information

\begin{tabular}{|l|c|c|c|}
\hline \multicolumn{1}{|c|}{ Variable } & Value & Frequency & Percentage \\
\hline \multirow{2}{*}{ Age } & $21-30$ & 196 & 80.7 \\
\cline { 2 - 4 } & $31-40$ & 47 & 19.3 \\
\hline \multirow{3}{*}{ Gender } & Male & 109 & 44.9 \\
\cline { 2 - 4 } & Female & 134 & 55.1 \\
\hline \multirow{4}{*}{ English learning (hours/week) } & $5-9$ & 96 & 39.5 \\
\cline { 2 - 4 } & $10-14$ & 112 & 46.1 \\
\cline { 2 - 4 } & $15-19$ & 29 & 11.9 \\
\cline { 2 - 4 } & $\geq 20$ & 6 & 2.5 \\
\hline
\end{tabular}

\subsection{Instruments}

The quantitative data in this study were collected using two questionnaires. The first was the Background Information Questionnaire, which was designed specifically for this study and consisted of two parts. The first part collected demographic data about the learners, including their age, gender, and the number of hours they spent learning English per week. The second part elicited the participants' self-rated English proficiency in the four skills of listening, speaking, reading, and writing. The participants were asked to self-rate their proficiency using a five-point Likert-scale consisting of the following ratings: 1 (poor), 2 (fair), 3 (good), 4 (very good), and 5 (excellent).

The second questionnaire was a modified version of Horwitz's (1985) 34-item BALLI. The original BALLI consists of five sections: 1. foreign language aptitude (Items 1, 2, 10, 15, 22, 29, 32, 33, 34); 2. the difficulty of language learning (Items 3, 4, 6, 14, 24, 28); 3. the nature of language learning (Items 5, 8, 11, 16, 20, 25, 26); 4. learning and communication strategies (Items 7, 9, 12, 13, 17, 18, 19, 21); and 5. motivations and expectations (Items 23, 27, 30, 31). It asks the participants to indicate the extent to which they agree with each statement using a five-point Likert-scale ranging from 1 (strongly agree) to 5 (strongly disagree). Since the participants in the present study were self-learners of English, as opposed to students in formal education settings, seven items were removed from the BALLI. These were Item 19: "If you are allowed to make mistakes in the beginning, it will be hard to get rid of them later on"; Item 21: "It is important to practice in the language laboratory"; Item 25: "Learning a foreign language is different from learning other school subjects"; and the items in the motivations and expectations section. The remaining 27 items were all relevant to the purpose of this study. Further, four items $(4,5,14,33)$ were slightly reworded for clarity and ease of assessment, as follows:

4. English is an easy language.

5. The structure of Arabic is different from that of English.

14. If someone spent one hour a day learning a language, it would take him/her 1-2 years to become fluent.

33. Saudis are good at learning foreign languages.

The modified questionnaire was then translated into the participants' first language, Arabic, and its internal consistency reliability was assessed, as will be explained in the next section.

The qualitative data were collected using one-on-one retrospective interviews, mainly to corroborate and interpret the questionnaire results. The participants were requested to elaborate on their questionnaire responses by answering the following questions:

- Why do you think so?

- Can you explain more?

- Can you give me an example? 


\subsection{Data Collection and Analysis}

To assess the internal consistency reliability of the questionnaire items, a pilot study was carried out with 50 participants who had similar characteristics to the sample of the main study. Cronbach's alpha coefficient was then computed, and the value obtained was .878 . Since this was above .7 , it was concluded that the modified version of the BALLI had high internal consistency reliability (see Brace et al., 2012; Nunnally, 1978; Pallant, 2020).

The collection of the main study data started in June 2019 and lasted approximately eight months. It began by locating and contacting the participants with the needed characteristics through friends and acquaintances. The identified participants were provided with an informed consent form and requested to sign and return it if they agreed to take part. They were assured that they could withdraw from the study at any time and that their personal information would be kept confidential and used for research purposes only. The researcher was keen to recruit a reasonably large sample (i.e., more than 200 participants) so that the possible presence of skewness or kurtosis values would not result in an underestimation of the variance in the data (Tabachnic \& Fidell, 2013, p. 8o). Therefore, the recruitment stopped when the total number of participants reached 250. After screening the questionnaires for missing data, the responses of seven participants were excluded; thus, the final sample size was reduced to 243 .

Subsequently, one-on-one retrospective interviews were conducted with 24 participants (11 males and 13 females) who volunteered to take part in this stage of the research. The interviews lasted between 30 and 45 minutes and were audio-recorded. They were conducted in Arabic to ensure accuracy of the responses.

The quantitative data from the two questionnaires were entered into IBM SPSS Statistics (version 26) for analysis. Descriptive statistics (frequencies and percentages) were computed for all items. The relationship between learner beliefs and self-rated proficiency was then calculated using the Pearson product-moment correlation coefficient $(r)$. The possible differences in beliefs according to gender and age group were examined using independent samples t-tests. After that, the interviews were transcribed, and the data were tabulated and categorized according to their relevance to the BALLI items.

\section{Results and Discussion}

\subsection{Research Question 1}

The first research question in this study investigated the beliefs that the participants held about foreign language learning. The findings generally indicated that the participants had strong beliefs about foreign language learning. Significantly, the neutral option, "neither agree nor disagree" was never selected by the majority of the participants for any item. While the findings generally confirmed those of the previous research in the Saudi context (Al-malki \& Javid, 2018; Al-Roomy, 2015; Alsamaani, 2012), a few significant differences were observed. These are highlighted in the relevant sections below.

\subsubsection{Foreign Language Aptitude}

Table 2: Percentages of Learners' Beliefs About Foreign Language Aptitude

\begin{tabular}{|c|c|c|c|c|c|}
\hline Item & Strongly agree & Agree & $\begin{array}{c}\text { Neither agree } \\
\text { nor disagree }\end{array}$ & Disagree & Strongly disagree \\
\hline 1 & 44.0 & 44.0 & 4.9 & 5.8 & 1.2 \\
\hline 2 & 3.3 & 4.1 & 4.1 & 47.7 & 40.7 \\
\hline 10 & 17.7 & 18.5 & 21.0 & 22.2 & 20.6 \\
\hline
\end{tabular}




\begin{tabular}{|c|c|c|c|c|c|}
\hline Item & Strongly agree & Agree & $\begin{array}{c}\text { Neither agree } \\
\text { nor disagree }\end{array}$ & Disagree & Strongly disagree \\
\hline 15 & 22.6 & 22.2 & 19.3 & 17.7 & 18.1 \\
\hline 22 & 18.1 & 26.3 & $19 \cdot 3$ & 16.5 & 19.8 \\
\hline 29 & 16.9 & 22.2 & 20.2 & 21.8 & 18.9 \\
\hline 32 & 43.2 & 39.5 & 8.2 & 9.1 & 0 \\
\hline 33 & 0 & 29.6 & 38.7 & 31.7 & 0 \\
\hline 34 & 44.0 & 44.9 & 4.9 & 6.2 & 0 \\
\hline
\end{tabular}

As the table reveals, the vast majority of the learners (88\%) agreed that learning a foreign language would be easier for children than for adults (Item 1). This finding supports the results of previous research showing that the earlier a foreign language is learned, the higher the likelihood of attaining native-like proficiency (see, for example, Lightbown \& Spada, 1993). Further, the majority of the learners $(88.4 \%)$ disagreed with the notion that "some people are born with a special ability which helps them learn a foreign language" (Item 2), and a similar percentage (88.9\%) believed that "everyone can learn to speak a foreign language" (Item 34). These findings are mostly in line with previous Saudi studies. The most notable difference, however, was that the largest percentages of learners in Alsamaani (2012) and Al-malki and Javid (2018) believed in the existence of an innate ability that helps some people learn foreign languages easily. Interestingly, a significant percentage of the learners (44.8\%) in the present study believed that they had "foreign language aptitude" (Item 15), which clearly indicates a high degree of self-confidence among the participants. Moreover, the interview data revealed that highly proficient learners felt more skilled at learning English than their less proficient counterparts. Nonetheless, the learners did not hold firm beliefs about the language learning capabilities of their fellow Saudis, as the largest percentage of them were neutral towards the statement "Saudis are good at learning foreign languages" (Item 33). On the other hand, a good percentage of the participants $(44.4 \%)$ believed that "women are better than men at learning foreign languages" (Item 22). These findings remind us of Horwitz's (1988, p. 288) caution that:

The concept of foreign language aptitude can be the source of a negative outlook on language learning. A student's belief that some people are unable, or at least less able, to learn a second language can lead to negative expectations about their own capability, especially when they are members of that particular group.

The results also showed that the majority of the learners $(82.7 \%)$ agreed that "people who speak more than one language well are very intelligent" (Item 32). As one interviewee explains, "Being a bilingual improves one's cognitive skills and strengthens brain muscles, which makes a person smarter." Nonetheless, the responses varied regarding whether or not "it is easier for someone who already speaks a foreign language to learn another one" (Item 10). The percentage of disagreement (42.8\%), however, was slightly higher for this item. Similarly, a few of the interviewees mentioned that they had already learned other foreign languages, such as French, Chinese, and Korean, but they did not feel that it facilitated their English learning in any way.

Lastly, the learners held different beliefs about whether or not "people who are good at math and science are not good at learning foreign languages" (Item 29). Interestingly, the interviewees who endorsed this statement interpreted it in light of the hemispheric dominance theory, which they indicated was manifested in their personal experiences. For example, one interviewee explained, "I am a left-brained person, so I am more logical and analytical in my thinking. I am really good with numbers but not that good at expressing myself in English. Perhaps I am not creative enough." On the other hand, an opponent of this theory commented, "I do not believe in the lateralization of brain function. If a person is smart enough to be good at math and science, then language learning would not be very challenging for them." While this finding confirms that of Al-malki and Javid (2018), it does not support the results of the Alsamaani (2012) and Al-Roomy (2015) studies, in which the largest percentages of the participants disagreed with this belief. 
Table 3: Percentages of Learners' Beliefs About the Difficulty of Language Learning

\begin{tabular}{|c|c|c|c|c|c|}
\hline Item & Strongly agree & Agree & $\begin{array}{c}\text { Neither agree } \\
\text { nor disagree }\end{array}$ & Disagree & Strongly disagree \\
\hline 3 & 41.2 & 50.2 & 8.6 & 0 & 0 \\
\hline 4 & 0 & 35.4 & 31.7 & 32.9 & 0 \\
\hline 6 & 21.0 & 35.4 & 20.2 & 9.9 & 13.6 \\
\hline 14 & 17.7 & 22.6 & 19.8 & 24.3 & 15.6 \\
\hline 24 & 18.1 & 27.6 & 19.3 & 17.3 & 17.7 \\
\hline 28 & 21.8 & 21.4 & 20.6 & 19.3 & 16.9 \\
\hline
\end{tabular}

One of the most interesting findings in this study was the extremely high agreement (91.4\%) among the learners with the belief that "some languages are easier to learn than others" (Item 3). The interviewees attributed this to the degree of similarity or difference between Arabic and the target language. They mentioned that some languages have a completely different alphabetic system, extremely complex grammar, or a wide range of tones. Regarding English, none of the participants strongly agreed or disagreed that it was "an easy language" (Item 4). Almost equal percentages of agreement, disagreement, and neutral responses were obtained for this item. In congruence with Horwitz's (1985) suggestion, the interviewees explained this finding in light of their previous learning experiences. One interviewee, for example, mentioned, "I understand English well and can express myself freely, so I think it is an easy language." Another interviewee, on the other hand, commented, "Even if I know some English words, I find it difficult to put them together while speaking. It is just difficult." More than half of the learners (56.4\%), however, believed that they would "ultimately learn to speak this language very well" (Item 6). This positive belief lies at the heart of the learning process, as persistence does ultimately help learners develop their communicative skills (Erlenawati, 2002). An interviewee, for example, mentioned, "Even if language learning is hard, it is not impossible. By being patient and making enough effort, we will eventually reach our goal." However, the responses were divided as to whether spending one hour a day learning a foreign language would be sufficient to achieve fluency in 1-2 years (Item 14). Some interviewees found this an unrealistic timeframe and believed that a minimum of three years would be required to attain fluency. Other interviewees, however, believed that individual differences could play a significant role in this regard. Some of the factors they mentioned included age, intelligence, and resourcefulness.

Regarding the four basic language skills, a large percentage of the learners (45.7\%) believed that speaking a foreign language was easier than understanding it (Item 24). A similar percentage (43.2\%) thought that reading and writing were easier than listening and speaking (Item 28). These findings are generally congruent with those of previous Saudi studies, with the exception that in Alsamaani (2012), almost equal percentages of learners had positive, negative, or neutral beliefs towards the easiness of visual skills over oral ones. This confirms Erlenawati's (2002, p. 325) observation that learners "show different perceptions of what is considered easy and difficult in language learning." It could also be interpreted in light of the learners' preferred learning styles. As one interviewee commented, "I am a visual learner. I find it much easier to understand something when I see it in front of me. Some people speak really fast or with a difficult accent, so I struggle to understand what they say." 


\subsubsection{Nature of Language Learning}

Table 4: Percentages of Learners' Beliefs About the Nature of Language Learning

\begin{tabular}{|c|c|c|c|c|c|}
\hline Item & Strongly agree & Agree & $\begin{array}{c}\text { Neither agree } \\
\text { nor disagree }\end{array}$ & Disagree & Strongly disagree \\
\hline 5 & 32.1 & 28.8 & 39.1 & 0 & 0 \\
\hline 8 & 34.6 & 20.6 & 25.5 & 19.3 & 0 \\
\hline 11 & 30.9 & 23.5 & 25.1 & 20.6 & 35.8 \\
\hline 16 & 0 & 0 & 31.3 & 32.9 & 33.3 \\
\hline 20 & 0 & 0 & 33.7 & 32.9 & 30.5 \\
\hline 26 & 0 & 0 & 36.6 & 32.9 & \\
\hline
\end{tabular}

As the results show, most of the learners (60.9\%) believed that the structures of Arabic and English are different (Item 5). Obviously, this is a realistic belief, especially since the two languages belong to different families - the former is a Semitic language, whereas the latter is an Indo-European one. As one interviewee commented, "I often have difficulty with English grammar; it is just different. In Arabic, we have nominal and verbal sentences, but in English there are only verbal sentences. I usually make mistakes when writing or speaking in English because its word order is different." Another interviewee mentioned, "In English, there are different verb tenses. There are also auxiliaries, like the verb 'be', which we do not often use in Arabic."

Further, more than half of the learners believed in the importance of knowing "the foreign culture in order to speak the foreign language" (Item 8) and in the advantages of learning "a foreign language in the foreign country" (Item 11). Interestingly, no strong disagreement was obtained for either of these statements. The learners thus advocated the idea of learning a foreign language through interaction with its native speakers. An interviewee, for example, mentioned that "the relationship between language and culture is very tight. People's cultures are reflected in their language, so we need to familiarize ourselves with it in order to understand their values and attitudes." Another interviewee commented, "Learning English abroad provides a richer input and more opportunities for communication in English. This is rare if I only learn the language here." An interviewee further added, "Native speakers use colloquial phrases and abbreviations that cannot be easily understood by foreigners. I think that daily exposure to their spoken English is really important."

A significant finding regarding the nature of foreign language learning was that almost twothirds of the learners disagreed that the process was mostly a matter of "learning a lot of new vocabulary words" (Item 16), "learning a lot of grammar rules" (Item 20), or "translating from Arabic" (Item 26). This finding diverges from what was reported by previous studies in Saudi Arabia, in which the majority of the learners endorsed all of these erroneous beliefs. As Erlenawati (2002, p. 334) suggests, "these beliefs may be rooted in their prior language learning experience, which was focused on the learning of grammar rules and vocabularies. Realistically, language learning requires more than just learning the vocabulary items and grammar rules; it also requires communicative skills that enable learners to use the language in a real context." Thus, it seems that the learners in the present study were at an advantage as they did not hold "a restricted view of language learning" (Horwitz, 1988, p. 288). An interviewee, for example, pointed out, "We do not need to memorize or to translate long lists of words to learn a foreign language. It is really boring. Continuous exposure to the foreign language through listening and reading is the best way to develop our skills." 
Table 5: Percentages of Learners' Beliefs About Learning and Communication Strategies

\begin{tabular}{|c|c|c|c|c|c|}
\hline Item & Strongly agree & Agree & $\begin{array}{c}\text { Neither agree } \\
\text { nor disagree }\end{array}$ & Disagree & Strongly disagree \\
\hline 7 & 1.2 & 33.7 & 27.6 & 36.2 & 1.2 \\
\hline 9 & 0 & 13.2 & 30.5 & 26.3 & 30.0 \\
\hline 12 & 25.5 & 24.3 & 29.2 & 21.0 & 0 \\
\hline 13 & 0 & 35.0 & 28.8 & 32.5 & 3.7 \\
\hline 17 & 55.1 & 44.9 & 0 & 0 & 0 \\
\hline 18 & 1.6 & 2.9 & 33.7 & 30.5 & 31.3 \\
\hline
\end{tabular}

The findings revealed that the learners were mixed in their beliefs about the importance of "speak[ing] a foreign language with an excellent accent" (Item 7), although the largest percentage of them disagreed with this belief. Interestingly, this is different from the findings of other Saudi studies, in which most learners believed in the importance of having a native-like accent when speaking a foreign language. While it is commonly believed that having a good accent is an indicator of high proficiency, that does not necessarily entail having a perfect accent or sounding like a native, as several factors, such as age and having a talent for mimicry, come into play here. Language learners should thus refrain from embracing such perfectionist views, as these can result in dissatisfaction and ultimately disengagement.

More than half of the learners (56.3\%) disagreed with Item 9, "You should not say anything in the foreign language until you can say it correctly." Although the appropriateness of guessing unknown words (Item 13) elicited different beliefs from the leaners, the largest percentage agreed with the use of this technique. It therefore appears that the learners in this study possessed one of the most important features of an effective language learner, that of risk-taking. As Brown (2007, p. 160) explains, "Risk-taking is an important characteristic of successful learning of a second language. Learners have to be able to gamble a bit, to be willing to try out hunches about the language and take the risk of being wrong."

The responses varied regarding the learners' willingness to practice the language with anyone they hear speaking it (Item 12). However, none of them strongly disagreed with this practice. There seems to be a link between this belief and resourcefulness. For instance, the interviewees who welcomed all possible opportunities for language practice reported that if they did not know a word in English, they would try various means, such as paraphrasing and even drawing, to communicate it to their interlocutor. On the other hand, a few interviewees were overwhelmed by the challenges involved and thus preferred to practice the language only when they were familiar with the topic and the appropriate vocabulary. Nonetheless, all the participants generally believed in the importance of repetition and continuous practice in the foreign language (Item 17), and a large percentage (61.8\%) disagreed with feeling "self-conscious speaking the foreign language in front of other people" (Item 18). Rather, they believed that their communication skills, as well as their general proficiency, would improve by practicing the language with other speakers. While this finding is in line with that of AlRoomy (2015), it does not support that of Alsamaani (2012), which was that most learners reported feeling uncomfortable when speaking English in the presence of others. This difference could probably be attributed to the different socio-demographic characteristics of the participants, such as their age and language learning context.

\subsection{Research Question 2}

The second research question in this study investigated the possible relationship between the learners' beliefs and their self-rated English proficiency. Table 6 demonstrates the participants' self- 
rated proficiency in each of the four basic skills of listening, speaking, reading, and writing.

Table 6: Percentages of Learners' Self-rated English Proficiency

\begin{tabular}{|c|c|c|c|c|c|}
\hline Skill & Poor & Fair & Good & Very good & Excellent \\
\hline Listening & 17.3 & 18.1 & 9.1 & 23.0 & 32.5 \\
\hline Speaking & 14.8 & 20.6 & 10.7 & 30.0 & 23.9 \\
\hline Reading & 13.2 & 22.2 & 4.9 & 30.0 & 29.6 \\
\hline Writing & 23.9 & 11.5 & 14.4 & 31.7 & 18.5 \\
\hline
\end{tabular}

The correlation between learner beliefs and self-rated proficiency was computed using the Pearson product-moment correlation coefficient $(r)$, and only one large, significant correlation at the .or level was obtained. This was between the learners' belief that they had foreign language aptitude (Item 15) and their self-rated English proficiency in the four basic skills of listening $(r=-.891)$, speaking $(r=$ $-.875)$, reading $(r=-.881)$, and writing $(r=-.883)$. Figure 1 illustrates the relationship between these variables.

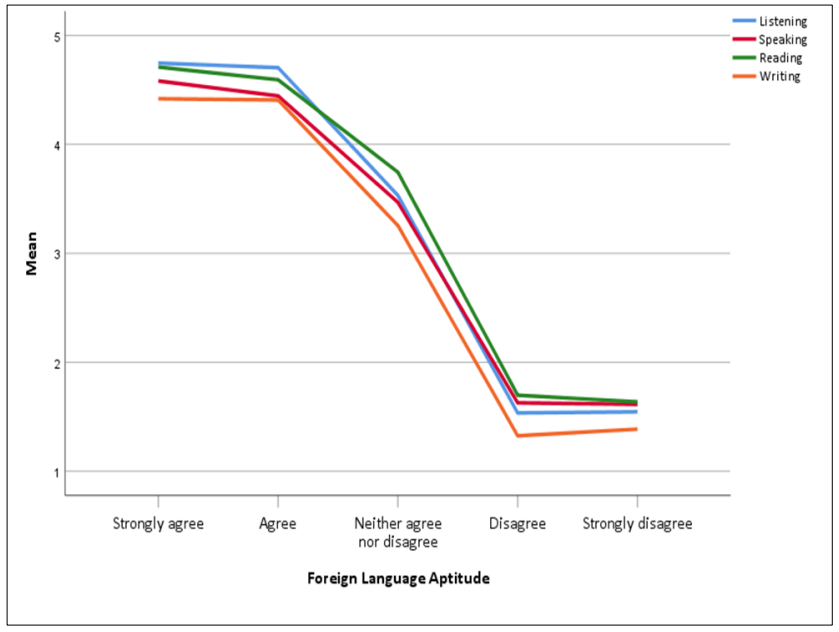

Figure 1: Relationship Between Foreign Language Aptitude and Self-rated Proficiency

As the figure shows, the learners who exhibited a higher agreement with this belief also rated themselves higher in English proficiency. This finding reminds us of Peacock's (1999, p. 258) caution that "some beliefs are detrimental to language learning," as learners might attribute the challenges they encounter when learning the language to their lack of aptitude, which could result in discontent and frustration (see also Horwitz, 1985; Mantle-Bromley, 1995). This was confirmed by the interviewees' responses. For example, an interviewee who self-rated herself as excellent in all four skills mentioned, "I feel I can speak and write English more clearly than most of my friends. I also understand it faster than them." On the other hand, an interviewee who rated her skills as poor commented, "I am very slow at learning English. I do not think I am talented enough to excel at it."

\subsection{Research Question 3}

Research question three investigated the possible differences in learners' beliefs according to their gender. An independent samples t-test was conducted to compare the scores of the male and female 
participants. The results showed a significant difference in the scores of males $(M=3.73, S D=.968)$ and females $(M=3.98, S D=.921 ; t(243)=-2.004, p=.046$, two-tailed) for Item 18 . The female learners disagreed with feeling "self-conscious speaking the foreign language in front of other people" more strongly than their male counterparts. However, the magnitude of the differences in the means (mean difference $=-.244,95 \% C l:-.483$ to -.004 ) was small (eta squared $=.016)$. Another significant difference was found in the scores of males $(M=3.14, S D=.775)$ and females $(M=2.93, S D=.782 ; t$ $(243)=2.113, p=.036$, two-tailed) for Item 33. The females believed that "Saudis are good at learning foreign languages" more strongly than the males. Similar to the previous result, the magnitude of the differences in the means (mean difference $=.212$, 95\% Cl: .014 to .410 ) was small (eta squared $=.018$ ). These beliefs seem to be pertinent to the female participants' high level of confidence. It was found that $61.5 \%$ of the female interviewees (compared to $54.6 \%$ of the males) reported feeling self-assured when using English for communication. Similarly, 46.2\% of the females (as opposed to $36.4 \%$ of the males) expressed confidence in their Saudi peers' abilities to learn and succeed in language learning. Figure 2 demonstrates the differences between the scores of the two groups of learners.

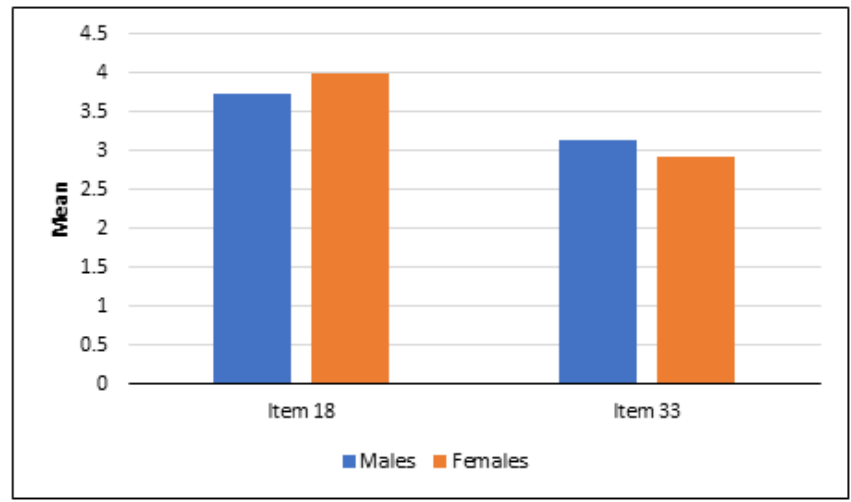

Figure 2: Differences in the Scores of Male and Female Learners

\subsection{Research Question 4}

To answer research question four, independent samples t-tests were also carried out to examine the differences in learners' beliefs according to their age. Significant differences were obtained for four items in the BALLI. First, a significant difference between the scores of the 21-30 age group $(M=3.80$, $S D=1.032)$ and the $31-40$ age group $(M=3.47, S D=.997 ; t(243)=1.968, p=.050$, two-tailed $)$ was obtained for Item 9 . The younger group disagreed with the statement "You should not say anything in the foreign language until you can say it correctly" more strongly than the older group. However, the magnitude of the differences in the means (mean difference $=.328,95 \% \mathrm{Cl}$ : .ooo to .656 ) was very small (eta squared $=.016$ ). In addition, a significant difference between the scores of the 21-30 age group $(M=1.41, S D=.493)$ and the $31-40$ age group $(M=1.62, S D=.491 ; t(243)=-2.611, p=.010$, twotailed) was obtained for Item 17. The younger group agreed with the importance of repetition and continuous practice of the foreign language more strongly than the older group. The magnitude of the differences in the means (mean difference $=-.209,95 \% \mathrm{Cl}:-.366$ to -.051 ) was also small (eta squared $=.028$ ). Confirming these results, the majority of the interviewees in the former group highly valued risk-taking and persistence and considered them an integral part of the language learning process.

Further, there was a significant difference in the scores of the 21-30 age group $(M=3.99, S D=$ $.823)$ and the 31-40 age group $(M=4.28, S D=.772 ; t(243)=-2.171, p=.031$, two-tailed $)$ for Item 16. 
The older group disagreed that "learning a foreign language is mostly a matter of learning a lot of new vocabulary words" more strongly than the younger group. Nevertheless, the magnitude of the differences in the means (mean difference $=-.287,95 \% \mathrm{Cl}:-.547$ to -.027 ) was small (eta squared $=$ .019). In addition, there was a significant difference in the scores of the 21-30 age group $(M=2.44, S D$ $=1.133)$ and the 31-40 age group $(M=2.00, S D=1.022 ; t(243)=2.588, p=.012$, two-tailed) for Item 11. The older group believed in the importance of "learn[ing] a foreign language in the foreign country" more strongly than the younger group. The magnitude of the differences in the means (mean difference $=.439,95 \% \mathrm{Cl}$ : .101 to .777 ) was also small (eta squared $=.027$ ). Similarly, very few differences were observed in the responses of the interviewees in both groups, which could be attributed to their personal experiences. For example, a participant in the older group stated, "Last year, I tried to memorize ten vocabulary items on a daily basis, but I had to quit after a few months as I eventually found that method to be ineffective to achieve my aspired proficiency." Another interviewee commented, "My cousin lived in the United States for only nine months, and his English improved dramatically. On the other hand, I have been learning English for almost two years without much success. I really believe that extensive exposure to the language is indispensable." The differences between the scores of the two groups of learners are illustrated in Figure 3.

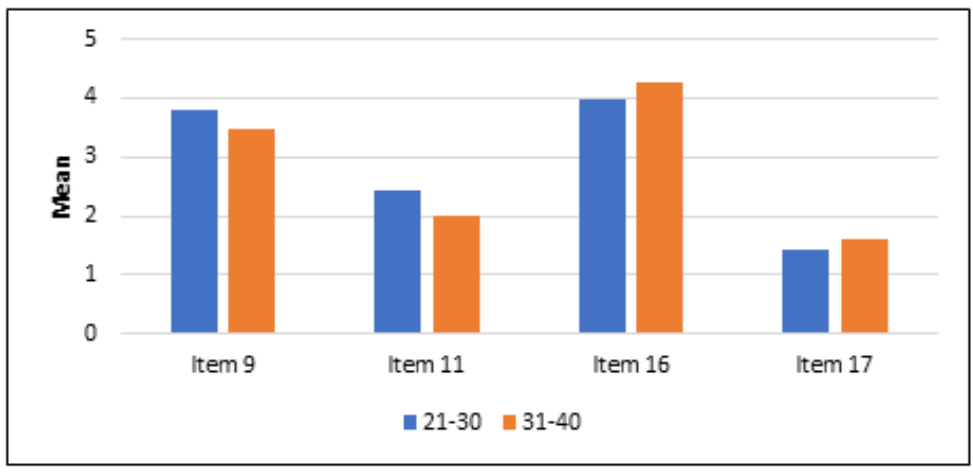

Figure 3: Differences in the Scores of the Two Age Groups

\section{Conclusion}

This research investigated the beliefs held by a group of Saudi self-learners of English as a foreign language. Unlike the findings reported by the majority of previous studies conducted with Saudi university students, the beliefs of the participants in the present research were found to be realistic. Since the participants in all of these studies shared the same cultural background, "it is entirely possible that age, stage of life, or language learning context [could] be important sources of withingroup variation in learner beliefs" (Horwitz, 1999, p. 575). Further, a significant positive correlation at the .or level was found between the learners' belief that they had foreign language aptitude and their self-rated English proficiency in the four skills of listening, speaking, reading, and writing. The results of the independent samples t-tests revealed two significant differences in learner beliefs according to gender and four significant ones according to age. The female learners disagreed with feeling "selfconscious speaking the foreign language in front of other people" more strongly than their male counterparts. The former group also believed that "Saudis are good at learning foreign languages" more strongly than the latter group. The younger age group disagreed with the statement "You should not say anything in the foreign language until you can say it correctly" more strongly than the older group. They also agreed with the importance of repetition and continuous practice of the foreign language more strongly than the older learners. The older group, on the other hand, 
disagreed that "learning a foreign language is mostly a matter of learning a lot of new vocabulary words" more strongly than the younger group. They also believed in the importance of "learn[ing] a foreign language in the foreign country" more strongly than the younger learners.

The aim of the present study was to expand our understanding of learner beliefs by drawing attention to a group of language learners that, although it has grown rapidly over the last few decades, is often neglected in foreign language studies. The variations observed within this group could possibly be attributable to the learners' prior learning experiences and individual characteristics. It is of utmost importance, however, to raise learners' awareness of the influence of the beliefs they bring to the language learning process on their ultimate success. Erroneous beliefs need to be modified in order to mitigate their negative consequences, such as learner dissatisfaction and frustration (see Erlenawati, 2002; Horwitz, 1987). More research in this area is needed, however, especially in different Saudi and Arab learning contexts. It is recommended that future studies conduct cross-sectional investigations to explore the beliefs held by self-learners of different cultural backgrounds or those learning languages that belong to different families. Longitudinal studies could also track these beliefs to examine their pattern of stability or change over time.

\section{Acknowledgements}

I would like to express my sincere appreciation to the participants for their invaluable contribution to this research.

\section{References}

Al-malki, E. A., \& Javid, C. Z. (2018). Identification of language learning beliefs among Saudi EFL learners. Arab World English Journal, 9(4), 186-199. https://dx.doi.org/10.24093/awej/volgno4.13

Al-Osaimi, S., \& Wedell, M. (2014). Beliefs about second language learning: The influence of learning context and learning purpose. The Language Learning Journal, 42(1), 5-24. http://dx.doi.org/10.108o/o9571736.2012.661753

Al-Roomy, M. (2015). Evaluating Saudi university students' beliefs about learning English. International Journal of English Linguistics, 5(1), 22-31. DOI: 10.5539/ijel.v5n1p22

Alsamaani, A. (2012). Assessing Saudi Learners' beliefs about English language learning. International Journal of English and Education, 1(2), 31-55.

Aziz, F., \& Quraishi, U. (2017). An insight into secondary school students' beliefs regarding learning English language. Cogent Education, 4(1), 1278835. https://doi.org/10.108o/2331186X.2017.1278835

Benson, P., \& Lor, W. (1999). Conceptions of language and language learning. System, 27(4), 459-472. https://doi.org/10.1016/So346-251X(99)0oo45-7

Brace, N., Snelgar, R., \& Kemp, R. (2012). SPSS for psychologists (5th ed.). Palgrave-McMillian.

Brown, D. (2007). Principles of language learning and teaching (5th ed.) Prentice Hall Regents.

Chawhan, L., \& Oliver, R. (200o). What beliefs do ESL students hold about language learning? TESOL in Context, $10(1), 20-27$.

Diab, R. L. (2006). University students' beliefs about learning English and French in Lebanon. System, 34(1), 8o96. https://doi.org/10.1016/j.system.2005.06.014

Erlenawati. (2002). Beliefs about language learning: Indonesian learners' perspectives, and some implications for classroom practices. Australian Journal of Education, 46(3), 323-337. http://dx.doi.org/10.1177/ooo494410204600306

Horwitz, E. K. (1985). Using students' beliefs about language learning and teaching in the foreign language methods course. Foreign Language Annals, 18(4), 333-34o. https://doi.org/10.111//j.1944-9720.1985.tbo1811.x

Horwitz, E. K. (1987). Surveying students' beliefs about language learning. In A. Wenden \& J. Rubin (Eds.), Learner strategies in language learning (pp. 119-132). Prentice-Hall International.

Horwitz, E. K. (1988). The beliefs about language learning of beginning university foreign language students. The Modern Language Journal, 72(3), 283-294. https://doi.org/10.2307/327506

Horwitz, E. K. (1999). Cultural and situational influences on foreign language learners' beliefs about language learning: A review of BALLI studies. System, 27(4), 557-576. https://doi.org/10.1016/So346-251X(99)ooo5o-o

Huang, S. C., \& Tsai, R. R. (2003). A comparison between high and low English proficiency learners' beliefs (ERIC Document Reproduction Service No. ED 482579). 
Kern, R. G. (1995). Students' and teachers' beliefs about language learning. Foreign Language Annals, 28(1), 71-92. https://doi.org/10.1111/j.1944-9720.1995.tboo770.x

Knowles, M. (1975). Self-directed learning: A guide for learners and teachers. Association Press.

Lightbown, P. M., \& Spada, N. (1993). How languages are learned. Oxford University Press.

Mantle-Bromley, C. (1995). Positive attitudes and realistic beliefs: Links to proficiency. The Modern Language Journal, 79(3), 372-386. https://doi.org/10.2307/329352

Mori, Y. (1999). Epistemological beliefs and language learning beliefs: What do language learners believe about their learning? Language Learning, 49(3), 377-415. https://doi.org/10.1111/o023-8333.00094

Nunnally, J. C. (1978). Psychometric theory (2nd ed.). McGraw-Hill.

Pallant, J. (2020). SPSS survival manual: A step by step guide to data analysis using IBM SPSS (7th ed.). Open University Press.

Peacock, M. (1999). Beliefs about language learning and their relationship to proficiency. International Journal of Applied Linguistics, 9(2), 247-263. https://doi.org/10.1111/j.1473-4192.1999.tboo175.x

Polat, N. (2009). Matches in beliefs between teachers and students, and success in L2 attainment: The Georgian example. Foreign Language Annals, 42(2), 229-249. https://doi.org/10.1111/j.1944-9720.2009.01019.X

Riley, P. A. (2009). Shifts in beliefs about second language learning. RELC, 40(1), $102-124$. https://doi.org/10.1177/0033688208101448

Sakui, S., \& Gaies, S. J. (1999). Investigating Japanese learners' beliefs about language learning. System, 27(4), 473492. https://doi.org/10.1016/So346-251X(99)ooo46-9

Tabachnic, B. G., \& Fidell, L. S. (2013). Using multivariate statistics (6th ed.). Pearson.

Tanaka, K., \& Ellis, R. (2003). Study-abroad, Language proficiency, and learner beliefs about language learning. JALT Journal, 25(1), 63-85. https://doi.org/10.37546/JALTJJ25.1-3

Wen, Q., \& Johnson, R. K. (1997). L2 learner variables and English achievement: A study of tertiary-level English majors in China. Applied Linguistics, 18(1), 27-48. https://doi.org/10.1093/applin/18.1.27

Wenden, A. L. (1986). What do second-language learners know about their language learning? A second look at retrospective accounts. Applied Linguistics, 7(2), 186-205. https://doi.org/10.1093/applin/7.2.186

Wenden, A. L. (1998). Metacognitive knowledge and language learning. Applied Linguistics, $19(4), 515-537$. https://doi.org/10.1093/applin/19.4.515

White, C. (1999). Expectations and emergent beliefs of self-instructed language learners. System, $27(4), 443-457$. https://doi.org/10.1016/So346-251X(99)0o044-5

Yang, N.-D. (1999). The relationship between EFL learners' beliefs and learning strategy use. System, 27(4), 515535. https://doi.org/10.1016/So346-251X(99)ooo48-2 